\title{
HUBUNGAN MALARIA DENGAN TNF- $\alpha$ DAN KADAR HEMOGLOBIN PADA IBU HAMIL DI KABUPATEN BOLAANG MONGONDOW UTARA
}

\author{
${ }^{1}$ Vincente L. Pranata \\ ${ }^{2}$ Joice N. A. Engka \\ ${ }^{3}$ Nelly Mayulu
}

\author{
${ }^{1}$ Kandidat Skripsi Fakultas Kedokteran Universitas Sam Ratulangi Manado \\ ${ }^{2}$ Bagian Fisiologi Fakultas Kedokteran Universitas Sam Ratulangi Manado \\ ${ }^{3}$ Bagian Gizi Fakultas Kedokteran Universitas Sam Ratulangi Manado
}

\begin{abstract}
As an infectious transmitted disease, malaria has been a tremendous health problem around the world. Indonesia is determined as one of the 104 malaria-endemic countries in the world. Pregnant women are easier infected by malaria compared with the general population. People suffered from malaria may have low haemoglobin and high TNF- $\alpha$ levels. The increased TNF $\alpha$ level may cause bad complication or mortality in malaria patient. This study aimed to determine the levels of hemoglobin and TNF- $\alpha$ among pregnant woman with malaria in Kabupaten Bolaang Mongondow Utara. This was a cross-sectional study. Samples were obtained by using purposive sampling method. Besides using questionnaire, there were three laboratory tests conducted in this study: peripheral blood smear with Giemsa staining for detection of plasmodia; hemoglobin level with rapid test hemoglobin; and TNF- $\alpha$ level with ELISA. The bivariate analysis showed that of 72 pregnant women there was only one (1.4\%) with positive malaria and increased TNF- $\alpha$ level. There was no pregnant woman with malaria had low hemoglobin level. The chi square test showed a P value $1,00(\alpha=0,05)$. Conclusion: There was no relation between plasmodium infection and the levels of TNF $\alpha$ and hemoglobin among pregnant women in Kabupaten Bolaang Mongondow Utara.
\end{abstract}

Keywords: hemoglobin, TNF- $\alpha$, malaria, pregnant woman

\begin{abstract}
Abstrak: Malaria merupakan penyakit menular yang menjadi masalah kesehatan masyarakat di dunia. Indonesia merupakan salah satu dari 104 negara yang termasuk negara endemis malaria. Wanita hamil lebih mudah terinfeksi malaria dibandingkan populasi umumnya. Malaria dapat menyebabkan penurunan kadar hemoglobin dan peningkatan kadar TNF- $\alpha$. Peningkatan kadar TNF- $\alpha$ dapat mengakibatkan komplikasi berat bahkan kematian pada penderita malaria. Penelitian ini bertujuan untuk mengetahui kadar TNF- $\alpha$ dan hemoglobin pada ibu hamil dengan malaria di Kabupaten Bolaang Mongondow Utara. Penelitian ini menggunakan desain potong lintang. Sampel diperoleh dengan metode purposive sampling. Selain kuesioner juga digunakan pemeriksaan laboratorium yaitu hapusan darah tepi dengan pengecatan Giemsa untuk deteksi plasmodium, kadar hemoglobin dengan rapid test hemoglobin, dan kadar TNF- $\alpha$ dengan teknik ELISA. Hasil analisis bivariat menunjukkan dari 72 ibu hamil hanya 1 orang $(1,4 \%)$ yang positif malaria dengan kadar TNF- $\alpha$ tinggi sedangkan kadar TNF- $\alpha$ yang normal dan positif malaria tidak ada $(0,00 \%)$. Analisis bivariat memperlihatkan dari 72 sampel ibu hamil ditemukan 1 sampel dengan kadar TNF- $\alpha$ meningkat dan positif malaria. Tidak ditemukan ibu hamil yang terinfeksi malaria dengan kadar hemoglobin rendah. Hasil uji chi square $(\alpha=0,05)$ menunjukkan nilai $P=1,00$. Simpulan: Tidak terdapat hubungan infeksi parasit plasmodium dengan kadar TNF- $\alpha$ dan hemoglobin pada ibu hamil di Kabupaten Bolaang Mongondow Utara.
\end{abstract}

Kata kunci: hemoglobin, TNF- $\alpha$, malaria, ibu hamil 
Malaria merupakan penyakit menular yang menjadi masalah kesehatan masyarakat, baik di dunia maupun di Indonesia. ${ }^{1}$ Berdasarkan The World Malaria Report 2012, tercatat 219 juta kasus malaria dengan 660.000 kematian di dunia yang terjadi pada tahun 2010 dan Indonesia merupakan salah satu dari 104 negara yang termasuk Negara endemis malaria. ${ }^{2}$ Wanita hamil lebih mudah terinfeksi malaria dibandingkan dengan populasi pada umumnya. Di daerah endemisitas tinggi, dimana penduduknya sudah mempunyai imunitas terhadap malaria, jarang terjadi malaria berat dan kematian, klinis yang ditimbulkan dan derajat parasitemia juga akan lebih berat pada ibu hamil primigravida dan berumur muda. ${ }^{3-5}$ Terdapat 4 jenis spesies parasit yang berbeda, yaitu Plasmodium falciparum, plasmodium vivax, plasmodium ovale dan plasmodium malariae. ${ }^{6}$ Malaria yang disebabkan oleh parasit dari genus Plasmodium dapat ditularkan melalui gigitan nyamuk anopheles. ${ }^{7}$ Anak-anak, ibu hamil, individu non-imun paling banyak terkena malaria oleh infeksi Plasmodium falciparum. $^{8}$

Pada wanita hamil yang terinfeksi malaria, eritrosit berparasit dijumpai pada plasenta sisi maternal dari sirkulasi tetapi tidak pada sisi fetal, kecuali pada penyakit plasenta. Pada infeksi aktif, plasenta terlihat hitam atau abu-abu dan sinusoid padat dengan eritrosit terinfeksi. Secara histologis ditandai oleh sel eritrosit berparasit dan pigmen malaria dalam ruang intervilli plasenta, monosit mengandung pigmen, infiltrasi mononuklear, simpul sinsitial, nekrosis fibrinoid, kerusakan trofoblas dan penebalan membran basalis trofoblas. Terjadi nekrosis sinsitiotrofoblas, kehilangan mikrovilli dan penebalan membran basalis trofoblas akan menyebabkan aliran darah ke janin berkurang dan akan terjadi gangguan nutrisi pada janin. Lesi bermakna yang ditemukan adalah penebalan membran basalis trofoblas, pengurusan mikrovilli fokal menahun. Bila villi plasenta dan sinus venosum mengalami kongesti dan terisi eritrosit berparasit dan makrofag, maka aliran darah plasenta akan berkurang dan ini dapat menyebabkan abortus, lahir prematur, lahir mati ataupun berat badan lahir rendah. ${ }^{7,9,10}$

Penurunan jumlah massa eritrosit dapat mengakibatkan kadar $\mathrm{Hb}$ menurun. ${ }^{11}$ Keseimbangan antara sitokin proinflamasi dan antiinflamasi menjadi hal yang sangat penting dan mempengaruhi perubahan kadar Hb. Ada empat sitokin yang berperan dominan pada malaria, yaitu IL-12, TNF- $\alpha$, IFN $\gamma$ dan IL-10. ${ }^{12}$ Dari beberapa penelitian dibuktikan bahwa penderita malaria serebral yang meninggal atau dengan komplikasi berat seperti hipoglikemia mempunyai kadar TNF $\alpha$ yang tinggi. Demikian juga malaria tanpa komplikasi kadar TNF- $\alpha$, IL-1, IL-6 lebih rendah dari malaria serebral. Pada kondisi tertentu TNF- $\alpha$ dapat melindungi, tetapi produksi yang berlebih dari TNF- $\alpha$ merusak hospes dan berperan pada patologi penyakit. ${ }^{12,13}$

Datukramat et al melaporkan prevalensi kejadian malaria untuk murid sekolah dasar di Kabupaten Bolaang Mongondow Utara didapatkan dari 110 responden terdapat 9 orang yang positif malaria. ${ }^{14}$

\section{METODE PENELITIAN}

Penelitian ini bersifat survei analitik dengan rancangan potong lintang. Subjek penelitian yaitu semua ibu hamil yang ada di wilayah 6 puskesmas yang ada di Kabupaten Bolaang Mongondow Utara dengan cara purposive sampling. Untuk kriteria inklusi yaitu seluruh ibu hamil trimester 2 dan 3, hadir pada saat diperiksa dan bersedia menjadi sampel.

Data yang telah dikumpulkan diolah menggunakan analisis univariat untuk mengetahui distribusi frekuensi dan proporsi masing-masing variabel yang diteliti, dan analisis bivariat untuk menunjukkan uji hubungan anatara variabel independen (malaria) dengan variabel dependen (kadar Hb dan TNF- $\alpha$ ). Analisis statistik menggunakan uji chi-square $\left(x^{2}\right)$ pada tingkat kemaknaan $95 \%(\alpha=0,05)$. 


\section{HASIL PENELITIAN}

Tabel 1 menunjukkan bahwa responden penelitian pada trimester 2 sebanyak 25 ibu hamil (35\%) dan pada trimester 3 sebanyak 47 ibu hamil (65\%). Tingkat pendidikan ibu terbanyak SMA yaitu 28 responden (39\%) dan paling sedikit S1 yaitu 2 responden (3\%), sedangkan pekerjaan ibu paling banyak sebagai IRT yaitu 67 responden (93\%) dan paling sedikit sebagai tenaga honorer yaitu 5 responden $(7 \%)$.

Tabel 1. Karakteristik responden penelitian

\begin{tabular}{|c|c|c|}
\hline $\begin{array}{c}\text { Karakteristik } \\
\text { Responden penelitian }\end{array}$ & $\mathrm{N}$ & $\%$ \\
\hline \multicolumn{3}{|l|}{ Trimester } \\
\hline 2 & 25 & 35 \\
\hline 3 & 47 & 65 \\
\hline \multicolumn{3}{|l|}{ Pendidikan Ibu } \\
\hline SD & 22 & 30 \\
\hline SMP & 20 & 28 \\
\hline SMA & 28 & 39 \\
\hline $\mathrm{S} 1$ & 2 & 3 \\
\hline \multicolumn{3}{|l|}{ Pekerjaan Ibu } \\
\hline Honorer & 5 & $7 \%$ \\
\hline IRT & 67 & $93 \%$ \\
\hline \multicolumn{3}{|l|}{ Pendidikan Suami } \\
\hline SD & 27 & 38 \\
\hline SMP & 22 & 30 \\
\hline SMA & 19 & 27 \\
\hline S1 & 4 & 5 \\
\hline \multicolumn{3}{|l|}{ Pekerjaan Suami } \\
\hline Sopir & 4 & 5 \\
\hline PNS & 2 & 3 \\
\hline Petani & 35 & 49 \\
\hline Wiraswasta & 18 & 25 \\
\hline Buruh & 9 & 13 \\
\hline Pekerjaan Swasta & 4 & 5 \\
\hline \multicolumn{3}{|l|}{ Pendapatan Perbulan } \\
\hline$<500.000$ & 7 & $9,7 \%$ \\
\hline $500.000-900.000$ & 38 & $53 \%$ \\
\hline $1.000 .000-2.000 .000$ & 26 & $36 \%$ \\
\hline$>2.000 .000$ & 1 & $1.3 \%$ \\
\hline Jumlah total & 72 & 100 \\
\hline
\end{tabular}

Tingkat pendidikan suami paling banyak SD yaitu 27 orang (38\%), paling sedikit S1 yaitu 4 orang (5\%).

Pekerjaan suami dari subjek penelitian paling banyak sebagai petani yaitu 35 orang (49\%), dan paling sedikit PNS yaitu
2 orang (3\%). Pendapatan keluarga subjek penelitian paling banyak Rp. 500.000900.000 yaitu 38 orang (53\%) dan paling sedikit $>$ Rp. 2.000 .000 yaitu 1 orang (1,38 \%) (Tabel 1).

\section{Analisis univariat}

Distribusi kadar $\mathrm{Hb}$ pada ibu hamil responden dengan kadar $\mathrm{Hb}$ rendah ialah 17 ibu hamil (23,6\%) sedangkan yang tidak anemia berjumlah 55 (76,4\%) ibu hamil (Tabel 2).

Tabel 2. Distribusi Kadar Hb pada ibu hamil di Kabupaten Bolaang Mongondow Utara

\begin{tabular}{ccc}
\hline Kadar Hb & Jumlah & $\%$ \\
\hline Rendah & 17 & 23,6 \\
Normal & 55 & 76,4 \\
Total & 72 & 100 \\
\hline
\end{tabular}

Distribusi malaria pada ibu hamil responden yang positif malaria hanya 1 orang $(1,4 \%)$ sedangkan yang negatif berjumlah 71 (98,6\%) orang (Tabel 3).

Tabel 3. Distribusi Malaria Pada Ibu Hamil di Kabupaten Bolaang Mongondow Utara

\begin{tabular}{ccc}
\hline Malaria & Jumlah & $\%$ \\
\hline Positif & 1 & 1,4 \\
Negatif & 71 & 98,6 \\
Total & 72 & 100 \\
\hline
\end{tabular}

Kadar TNF- $\alpha$ yang tinggi pada $10 \mathrm{ibu}$ hamil sedangkan yang normal berjumlah 62 orang (86,1\%) (Tabel 4).

Tabel 4. Kadar TNF- $\alpha$ Pada Ibu Hamil di Kabupaten Bolaang Mongondow Utara

\begin{tabular}{ccc}
\hline TNF- $\alpha$ & Jumlah & $\%$ \\
\hline Normal & 62 & 86,1 \\
Tinggi & 10 & 13,9 \\
Total & 72 & 100 \\
\hline
\end{tabular}

\section{Analisis bivariat}

Hasil analisis bivariat menunjukkan dari 72 ibu hamil hanya 1 orang $(1,4 \%)$ yang positif malaria dengan kadar TNF $\alpha$ tinggi sedangkan kadar TNF $\alpha$ yang normal dan positif malaria tidak ada (0,00\%). Ibu 
hamil yang tidak terinfeksi malaria dengan TNF $\alpha$ tinggi berjumlah 10 orang (13,9\%) sedangkan kadar TNF $\alpha$ yang normal berjumlah 61 orang $(84,7 \%)$.

Tabel 5. Distribusi Hubungan Infeksi Malaria dengan kadar TNF a Pada Ibu Hamil di Kabupaten Bolaang Mongondow Utara

\begin{tabular}{|c|c|c|c|c|c|c|}
\hline \multirow{3}{*}{$\begin{array}{l}\text { Infeksi } \\
\text { Malaria }\end{array}$} & \multicolumn{4}{|c|}{ TNF $\alpha$} & \multirow{3}{*}{ Total } & \multirow{3}{*}{$P$} \\
\hline & \multicolumn{2}{|c|}{ Tinggi } & \multicolumn{2}{|c|}{ Normal } & & \\
\hline & $\mathrm{n}$ & $\%$ & $\mathrm{n}$ & $\%$ & & \\
\hline Positif & 1 & 1,4 & 0 & 0,00 & 1 & 0 \\
\hline Negatif & 10 & 3,9 & 61 & 84,7 & 71 & 000 \\
\hline
\end{tabular}

Pada Tabel 6, hasil analisis menunjukkan dari 72 orang ibu hamil dengan kadar $\mathrm{Hb}$ normal dan positif infeksi malaria hanya 1 orang ibu hamil $(1,4 \%)$ dan tidak terdapat ibu hamil dengan kadar $\mathrm{Hb}$ rendah dan positif infeksi malaria (0,00\%). Kadar $\mathrm{Hb}$ normal dan negatif infeksi malaria berjumlah 54 orang ibu hamil $(75,0 \%)$ sedangkan kadar Hb rendah dan negatif malaria berjumlah 17 orang ibu hamil (23,6\%).

Hasil uji Chi Square pada tingkat kemaknaan 95\% menunjukkan nilai $p=$ 1,000 sehingga nilai $p$ lebih besar dari $\alpha=$ 0,05 menunjukkan bahwa tidak terdapat hubungan antara kadar $\mathrm{Hb}$ dan TNF $\alpha$.

Tabel 6. Distribusi hubungan infeksi malaria dengan kadar $\mathrm{Hb}$ pada ibu hamil di Kabupaten Bolaang Mongondow Utara

\begin{tabular}{ccccccc}
\hline \multirow{2}{*}{$\begin{array}{c}\text { Infeksi } \\
\text { Malaria }\end{array}$} & \multicolumn{4}{c}{ Kadar Hb } & & \multirow{2}{*}{ Normal } \\
\cline { 2 - 5 } & $\mathrm{n}$ & $\%$ & $\mathrm{n}$ & $\%$ & & \\
\hline Positif & 1 & 1,4 & 0 & 0 & 1 & 1,000 \\
\hline Negatif & 54 & 5,0 & 7 & 3,6 & 71 & \\
\hline
\end{tabular}

\section{BAHASAN}

Pada penelitian ini, dari 72 survei sampel ibu hamil di Kabupaten Bolaang Mongondow Utara, ditemukan 11 orang ibu hamil dengan kadar TNF $\alpha$ tinggi sedangkan 61 orang dengan kadar TNF $\alpha$ normal. Ditemukan juga 55 orang ibu hamil dengan kadar $\mathrm{Hb}$ normal dan 17 orang ibu hamil dengan kadar $\mathrm{Hb}$ rendah.
Hasil uji Chi Square menunjukkan tidak adanya hubungan antara kadar $\mathrm{Hb}$, TNF $\alpha$ dan malaria pada ibu hamil karena nilai $p$ lebih besar dari nilai $\alpha$.

Menurut Feiko ter Kuile, pada tahun 2007 didapat bahwa setiap tahunnya tidak kurang dari 125 juta wanita hamil ditemui pada daerah endemis malaria. Mereka merupakan kelompok resiko tinggi untuk menderita berbagai komplikasi yang meliputi $60 \%$ dari seluruh kehamilan di dunia. Terdapat 10.000 wanita dan 20.000 bayi meningal setiap tahun yang disebabkan oleh malaria. ${ }^{15}$

Penelitian yang dilakukan oleh Irawati Lili di RS. Dr. M. Djamil Padang dan RS swasta Padang untuk pasien yang berusia lebih dari 12 tahun tentang hubungan antara TNF $\alpha$ dengan kadar $\mathrm{Hb}$ pada parasitemia menunjukkan hubungan yang tidak bermakna tetapi data menunjukkan adanya korelasi positif antara TNF $\alpha$ dengan penderita malaria falciparum. ${ }^{16}$

Menurut penelitian yang dilakukan oleh Loka Litbang P2B2 Baturaja adanya error rate yang mencapai 55,2\% untuk pemeriksaan sediaan darah malaria. Terdapat dua kemungkinan yang dapat terjadi dalam pemeriksaan sediaan darah yaitu positif palsu dan negatif palsu. Beberapa faktor yang menyebabkan ini yaitu faktor petugas dengan tingkat pendidikan, pengalaman bekerja, umur dan keterampilan. Selain itu, faktor sarana seperti mikroskop, kualitas Giemsa, kualitas kaca sediaan, dan kualitas sediaan darah seperti faktor tebalnya sediaan darah. $^{17}$

\section{SIMPULAN}

Dari hasil penelitian yang dilaksanakan pada ibu hamil di Kabupaten Bolaang Mongondow Utara dapat disimpulkan bahwa tidak terdapat hubungan antara infeksi parasit plasmodium dengan kadar hemoglobin dan TNF- $\alpha$.

\section{SARAN}

Disarankan untuk melakukan pemeriksaan darah rutin pada ibu hamil yang terkena malaria. Pengobatan ibu 
hamil yang terinfeksi parasit malaria perllu dilakukan untuk mengurangi angka kematian janin akibat infeksi parasit malaria

Penelitian lanjutan saat pemeriksaan darah malaria harus dilakukan lebih teliti agar tidak terjadi error rate.

\section{DAFTAR PUSTAKA}

1. Kementerian Kesehatan RI. Epidemiologi Malaria di Indonesia. Jakarta: Kementerian Kesehatan RI, 2011.

2. WHO. World Malaria Report. Geneve: WHO, 2012.

3. Cahaya I. Pengaruh malaria selama kehamilan. USU digital library 2003 Medan: Universitas Sumatera Utara, 2003.

4. Quinn TC. Parasitic Disease during Pregnancy. Sciarra JJ, Eschenbach DA, Depp R, editors. In: Gynecology and Obstetrics Volume 3. Philadephia: JB Lippincott Company, 1992; p. 1-6.

5. Raghupathy $\mathbf{R}$. Th1-type immunity is incompatible with successful pregnancy. Immunol Today. 1997;18:478-82.

6. WHO. Malaria. (cited 2015 Jan 16). Available from: http://www.wpro.who.int/health_topics/mal aria/overview.htm.

7. Astuty, Hendri, Pribadi W. Epidemiologi malaria. In: Parasitologi Kedokteran (Edisi ke-4). Jakarta: FKUI, 2008.

8. Suparman E. Malaria pada Kehamilan. CDK. 2005;146:19-28.

9. Shulman CE, Marshall T, Dorman EK, et al. Malaria in pregnancy: adverse eff ects on haemoglobin levels and birthweight in primigravidae and multigravidae. Trop Med Int Health. 2001;6:770-8.

10. Eritropoiesis dan Aspek Umum Anemia. In: Hematologi. Jakarta: EGC, 2009.
11. Differentiation of plasma IL-10 TNF ratio between malaria falciparum patients with anemia and without anemia 2010 [cited 2015 Jan 16]. Available from: http://www.fkunair.ac.id/scientificpapers/p enelitian-uppm-fk-unair/

12. Chen K, Suhendro, Nainggolan $L$. Malaria. In: Sudoyo AW, Setiyohadi B, Alwi I, Simadibrata M, Setiati S, editors. Buku Ajar Ilmu Penyakit Dalam Jilid III (4th ed). Jakarta: Departemen Ilmu Penyakit Dalam FKUI, 2006.

13. Datukramat MD, Mayulu N, Masi G. Hubungan Sanitasi Lingkungan Dengan Kejadian Malaria Pada Murid Sekolah Dasar Di Kabupaten Bolaang Mongondow Utara. eKp. 2013;1(1).

14. World Health Organization. 2011. [cited 2014 Jan 16]

15. Hidayat A, Dachlan EG, Prasetyo B, Basuki S. Hasil pemeriksaan mikroskopis dan PCR malaria dari darah tepi, jaringan plasenta dan darah tali pusat pada ibu bersalin yang mendapat terapi ACT. Studi operasional pada empat kecamatan di Kabupaten Indragiri Hilir Propinsi Riau Majalah Obstetri \& Ginekologi. 2011;19(3):113-20.

16. Irawati L. Hubungan Tumor Necrosis Factor-Alfa (Tnf-A) dengan Kadar Hemoglobin dan Parasitemia Pada Infeksi Malaria Falciparum. Jurnal Kesehatan Andalas. 2014;3(2):98-101.

17. Endah A, Riyanti E, Prasetyorini B, Aisyah, Handayani KS, Tjitra E. Cek Silang Mikroskopis Sediaan Darah Malariapada Monitoring Pengobatan Dihidroartemisinin-Piperakuin Di Kalimantan dan Sulawesi. Media Litbang Kesehatan. 2012;22(4):167-72. 